\title{
Congress split over funding for 'safe' nuclear reactor
}

Geoff Brumfiel, Washington

Friends and foes of nuclear power in the United States are battling over a proposal to spend up to $\$ 1.1$ billion on an

'intrinsically safe' fission-reactor design.

Supporters of the plan, led by Senator

Pete Domenici (Republican, New Mexico), have allocated $\$ 30$ million for it in the Senate version of next year's funding bill for the Department of Energy. But the House version makes no such provision, and the project's immediate fate will be determined at a conference between the two sides in the next few weeks.

The proposed reactor at the Idaho National Environmental and Engineering Laboratory near Idaho Falls would burn pellets of uranium fuel just $\mathbf{0 . 5}$ millimetres in diameter. Some five billion of the pellets would either be fused into billiard-ball-sized graphite spheres or encased in a honeycomb-like graphite structure. The system would be cooled by helium circulating at nearly $1,000{ }^{\circ} \mathrm{C}$, which could directly drive turbogenerators. Advocates of the design claim that the helium could also be used to generate hydrogen for use as fuel.

"This new reactor will also be inherently safe," says Jim Lake, associate director of nuclear energy at the Idaho lab. In the event of coolant loss, the core will reach $15,000^{\circ} \mathrm{C}$ but will not melt down, he says, because of graphite's high heat tolerance.

Critics counter that the design has other safety problems. "Graphite can't melt, but it can catch fire," says David Lochbaum, a nuclear engineer with the Union of Concerned Scientists, a non-profit environmental group.

Chris Paine of the Natural Resources Defense Council, another environmental group, doubts that generating large quantities of flammable hydrogen at a nuclear reactor will ever be safe or economic. "The capital costs of generating hydrogen from a nuclear reactor are absurdly high," he says. "It makes no sense."

Andy Kadak, a nuclear engineer at the Massachusetts Institute of Technology, says that a graphite fire is unlikely, and that hydrogen could be generated in buildings a safe distance from the reactor at off-peak times.

An energy bill that would recommend spending $\$ 1.1$ billion on the project over the next five years is being held up by disputes over unrelated issues, such as energy regulation.

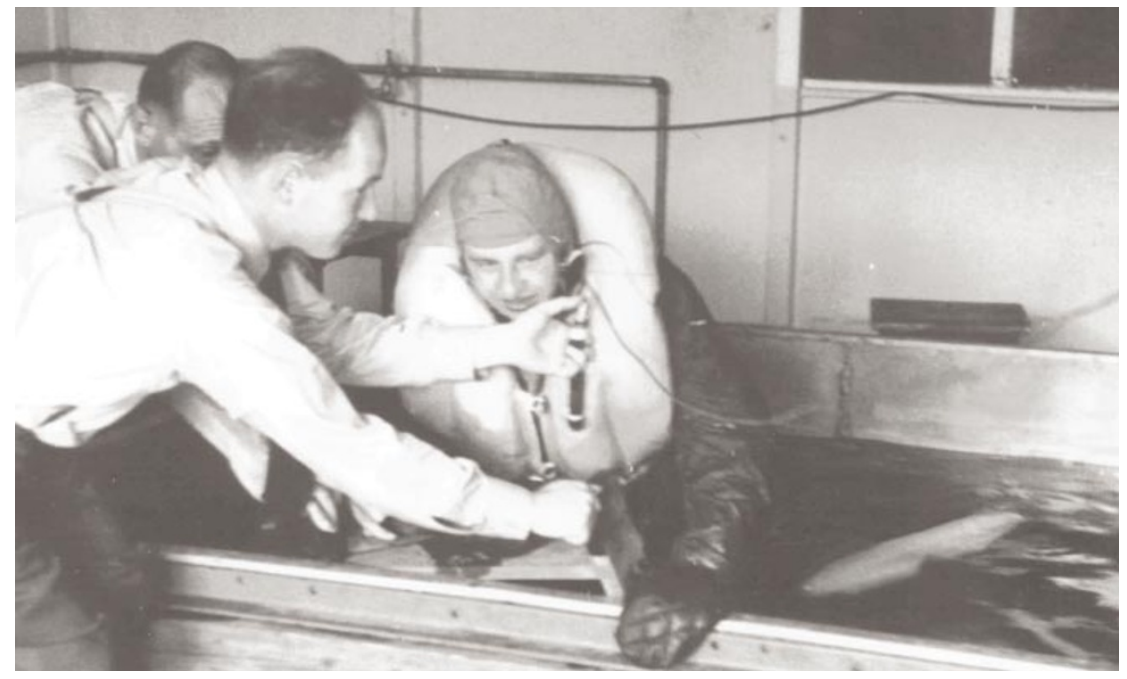

Military physicians at the Dachau concentration camp tested the effects of icy water on prisoners.

\section{Quirin Schiermeier, Munich}

Germany's scientific establishment was more thoroughly captivated by Nazi thinking than has ever been admitted, according to freshly collated documentary evidence.

The DFG, Germany's main research agency, is sponsoring a re-evaluation of its role in the period surrounding the Second World War. Science historians who met in Heidelberg last week to discuss this reported that the agency funded exploitative and unethical research between 1933 and 1945 across several disciplines, including medicine, physiology and psychiatry. Several participants said that any view that German science was not totally corrupted by Nazi ideology should be revised.

The agency has only recently begun to assess its Nazi past. It commissioned a book on the subject from the historian Notker Hammerstein, which was published in 1999 and roundly criticized for its apologetic tone and its tendency to downplay links between the DFG and medical war crimes (see Nature 398, 274; 1999).

The DFG then took a second, more comprehensive approach. It commissioned a working group to prepare for critical analysis tens of thousands of archived letters and reports relating to projects funded between 1920 and 1970. It then set up a five-year programme, comprising 14 peer-reviewed sub-projects, aimed at investigating DFGfunded research throughout the period.

"We have proven that the DFG was willingly involved in the full range of medical crimes during the Nazi era," says Wolfgang Eckart, head of the history of medicine at the University of Heidelberg and the organizer of last week's meeting.

Correspondence between grant applicants and Ferdinand Sauerbruch, then head of the DFG's medical section, supports the view that the DFG leadership was fully informed about inhuman medical-research projects. In one letter, Otmar von Verschuer, director of the Kaiser Wilhelm Institute for Anthropology in Berlin, enthused about "excellent conditions for researchers in Auschwitz". Others express appreciation for the "wonderful brains" obtained from a euthanasia centre in Brandenburg-Görden, where at least 9,000 people, including many children, were killed.

The meeting was also given evidence that the DFG actively supported notorious human experiments. In the Dachau concentration camp, for example, tropical-disease expert Klaus Schilling infected 1,200 prisoners of war, including many Polish priests, in search of a malaria vaccine. About 400 died.

"During the war, the DFG deliberately subordinated medical ethics to the production of fast results," says Marion Hulverscheidt, a science historian at the University of Heidelberg. "Malaria experiments were supported against scientific advice, and even though valid animal models were available."

After Hitler came to power, the DFG became a de facto Nazi organization. Ordinary research was not eliminated, but it is a "myth" that science remained neutral and pluralistic, says Ulrich Herbert, a historian at the University of Freiburg, who co-chaired the investigation.

Allied intervention put a stop to medical crimes in May 1945, but Nazi ideas in the social sciences and humanities can be tracked until the 1960s, he says. "It becomes ever more evident that the DFG was a basic part of the system," says Guido Lammers, the DFG programme director who is overseeing the assessment. "There is a strong case for us to revise our history." 